OPEN ACCESS

Edited by:

Timothy Ravasi,

Okinawa Institute of Science and Technology Graduate University,

Japan

Reviewed by:

Heather Diana Veilleux,

University of Alberta, Canada

Yuan-Ye Zhang,

Xiamen University, China

*Correspondence.

Amélie Crespe

amelie.crespe/@gmail.com orcid.org/0000-0002-6351-9008

Naim M. Bautista

naimbautista05@gmail.com

orcid.org/0000-0003-0634-0842

Specialty section:

This article was submitted to Global Change and the Future Ocean,

a section of the journal

Frontiers in Marine Science

Received: 22 June 2021

Accepted: 26 August 2021

Published: 22 September 2021

Citation:

Bautista NM and Crespel A (2021)

Within- and Trans-Generational

Environmental Adaptation to Climate

Change: Perspectives and New

Challenges.

Front. Mar. Sci. 8:729194.

doi: 10.3389/fmars.2021.729194

\section{Within- and Trans-Generational Environmental Adaptation to Climate Change: Perspectives and New Challenges}

\author{
Naim M. Bautista ${ }^{1,2 *}$ and Amélie Crespe/ ${ }^{3 *}$ \\ ${ }^{1}$ Department of Biology, Aarhus University, Aarhus, Denmark, ${ }^{2}$ School of Biological Sciences, University \\ of Nebraska-Lincoln, Lincoln, NE, United States, ${ }^{3}$ Department of Biology, University of Turku, Turku, Finland
}

The current and projected impacts of climate change are shaped by unprecedented rates of change in environmental conditions. These changes likely mismatch the existing coping capacities of organisms within-generations and impose challenges for population resilience across generations. To better understand the impacts of projected scenarios of climate change on organismal fitness and population maintenance, it is crucial to consider and integrate the proximate sources of variability of plastic and adaptive responses to environmental change in future empirical approaches. Here we explore the implications of considering: (a) the variability in different time-scale events of climate change; (b) the variability in plastic responses from embryonic to adult developmental stages; (c) the importance of considering the species life-history traits; and (d) the influence of trans-generational effects for individual survival and population maintenance. Finally, we posit a list of future challenges with questions and approaches that will help to elucidate knowledge gaps, to better inform conservation and management actions in preserving ecosystems and biodiversity.

Keywords: climate fluctuation, evolution, developmental plasticity, trans-generational effects, adaptation, lifehistory trait

\section{INTRODUCTION}

Global climate change is projected to continue modifying environmental conditions at unprecedented rates (Lüthi et al., 2008; IPCC, 2014). These changes have dramatic consequences for ecosystems and communities by reducing species abundance and in extreme cases causing species extinction (Thomas et al., 2004; Willis et al., 2008; Hoffmann and Sgrò, 2011), leading to decreased biodiversity (Parmesan and Yohe, 2003; Landman et al., 2005; Burlakova et al., 2014; Zhang et al., 2018). In aquatic systems, the effects of climate change include, among others, fluctuations in oxygen availability, increased acidification, and extreme stochastic temperature events (Caldeira and Wickett, 2005; IPCC, 2014; Jenny et al., 2016; Dahlke et al., 2020). The magnitude, duration, and periodicity of these changes likely mismatch the existing evolved coping capacities of species, compromising population maintenance and resilience (Johansen et al., 2021). Mitigation of the effects of climate change can take place within and across generations. Withingenerational mitigation can occur through relocation to more favorable environments (Pinsky et al., 2013). However, when relocation is not feasible, within-generational mitigation can then 
occur through individual acclimatization by phenotypic plasticity (Crozier and Hutchings, 2014). If individuals of a population survive and are able to reproduce, the effects of climate change can then be attenuated across generations via nongenetic inheritance or genetic adaptation (Gienapp et al., 2008; Andrewartha and Burggren, 2012; Ryu et al., 2020).

To better understand the impacts of projected scenarios of climate change on individual fitness, population maintenance, and species resilience, it is thus crucial to frame future experimental studies under an integrative approach that considers how the proximate environmental causes of individual variability that affect plastic responses can influence the ultimate functional and potential adaptive responses to environmental change. As the number of studies on climate change increases, the complexity of its effects becomes more evident. In fact, these advances bring along new challenges for the scientific community, such as providing more ecologically relevant predictions that integrate natural-field conditions in experimental designs while overcoming technological and logistic constraints.

In this perspective we focus on aquatic systems to first highlight the importance of considering different time scales of fluctuations in environmental conditions, for example, comparing the effects of short-term variations (i.e., daily fluctuations) to long-term projected scenarios (i.e., average changes of climate change). Second, depending on the environmental condition, the organismal physiological capacities to cope with disturbances partially depend on the "maturity" of its organs and systems. Therefore, variability in plastic responses to environmental challenges within a population will likely arise based on the organism's developmental stage. Third, species' life history traits (e.g., life span, generational time, and reproductive strategy) rely on the availability of resources through time and location. However, variability within and across habitats imposes challenges on fitness. Thus, it becomes important to determine how climatic variability will impact life history traits, as well as to determine if the response to these challenges will be similar across species with different life histories. Fourth, we discuss how within-generational responses to fluctuations in environmental conditions can affect the phenotype of subsequent offspring generations, and potentially induce genetic adaptation. Finally, we list potential directions for future experimental studies that will provide more realistic predictions of the consequences of climate change on populations.

\section{TIME-SCALE EVENTS: WEATHER, CLIMATE, AND CLIMATE CHANGE}

Climate change refers to significant long-term changes in average environmental conditions. These changes include, among others, modifications of temperature cycles, carbon dioxide and oxygen levels, $\mathrm{pH}$ of water, precipitation, and wind patterns (Burroughs, 2007; Bopp et al., 2013). Although these variables fluctuate naturally and impose constant challenging conditions for individuals and populations, their occurrence, variability, amplitude, and unpredictability have been exacerbated since the industrial revolution (Jenny et al., 2016; Johansen et al., 2021; Figure 1A). Strikingly, most of the studies aimed at understanding the effects of climate change consider discrete stepwise changes of a selected "stressor" that reflect the mean values of long-term predicted scenarios. Commonly, after exposing the study species to the new steady level, a description of the organismal (or population) responses and speculations about their adaptive capacity are provided (e.g., Rosa et al., 2014; Rummer et al., 2014; Dixson et al., 2015; Faria et al., 2018; Johansen et al., 2021). For example, studies investigating the effects of global warming and ocean acidification generally expose the individuals to a constant $+3^{\circ} \mathrm{C}$ or $-0.3 \mathrm{pH}$ units, respectively, before assessing individual fitness related traits, such as growth and survival (Sheppard-Brennand et al., 2010; McLeod et al., 2013; Rasconi et al., 2015; Crespel et al., 2017; Qui-Minet et al., 2019). However, in nature, ambient conditions rarely, if ever, change in a stepwise fashion, and organisms face fluctuations in environmental conditions at time scales of hours, days, months, and years (Burggren, 2018). Recent studies have highlighted that the responses of individuals within a population will vary when exposed to a constant or fluctuating conditions (Drake et al., 2017; Hannan et al., 2020). Therefore, to better understand the impacts of climate change on organisms and populations, it is necessary to integrate more naturally relevant variability of environmental conditions in experimental designs and to differentiate the effects of stochastic weather events -short-term every day and weekly changes in ambient conditions- from those of climate -seasonal and yearly changes in ambient conditions- and climate change -predicted changes in mean values of environmental parameters across decades and centuries- (Burroughs, 2007; Figure 1A).

Habitats vary in their capacities for buffering changes in environmental conditions (Malhi et al., 2020), and their resident species reflect this variation. Nonetheless, even if organisms are physiologically able to cope with the environmental stress imposed by a single extreme event (e.g., heat waves), it is possible that repeated and long-term exposure to unpredictable conditions will likely outweigh their existing evolved coping capacities (Le Nohaïc et al., 2017; Johansen et al., 2021)compromising survival and contribution to future generations. For example, thermally resistant corals from Northwestern Australia that have been able to thrive in daily temperatures up to $37^{\circ} \mathrm{C}$, experienced severe mass bleaching $(<80.6 \%)$ in 2016 due to extreme heatwaves of $4.5-9.3^{\circ}$ heating weeks for about 5 months (Le Nohaic et al., 2017). This study highlights the importance of considering both, stochastic extreme weather events as well as medium- and long-term natural climatic variability in experimental designs.

Noteworthy is the fact that the combination of environmental stressors -which is the norm more than the exception in nature- can have antagonistic, additive or synergetic effects on organisms and populations (Darling and Côté, 2008; Lefevre, 2016; Montgomery et al., 2019). For example, oxygen consumption of marine ectotherms is more commonly affected by additive or antagonistic interactions between ocean warming and acidification than by a synergistic effect (see Lefevre, 2016; Pistevos et al., 2016; Leo et al., 2017). Consequently, the empirical 
A

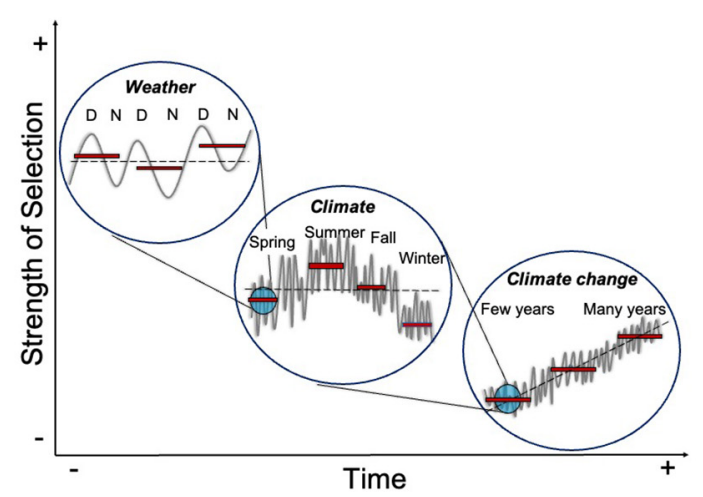

C

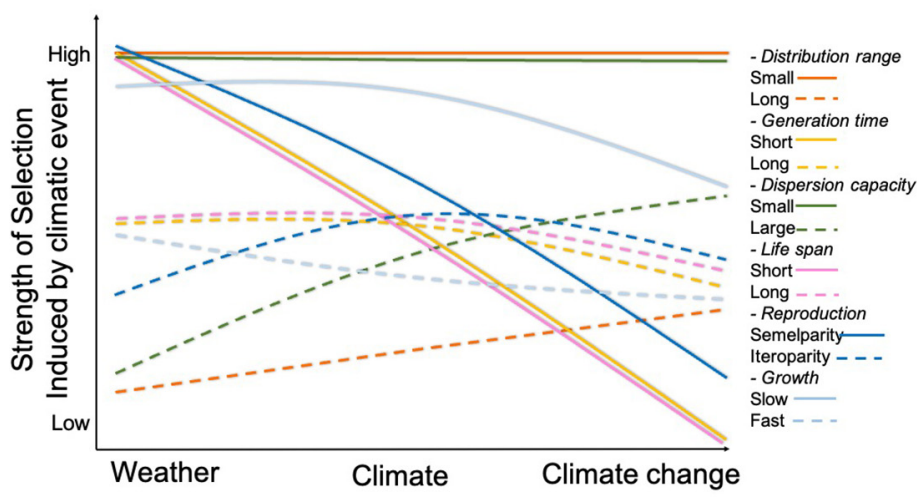

B

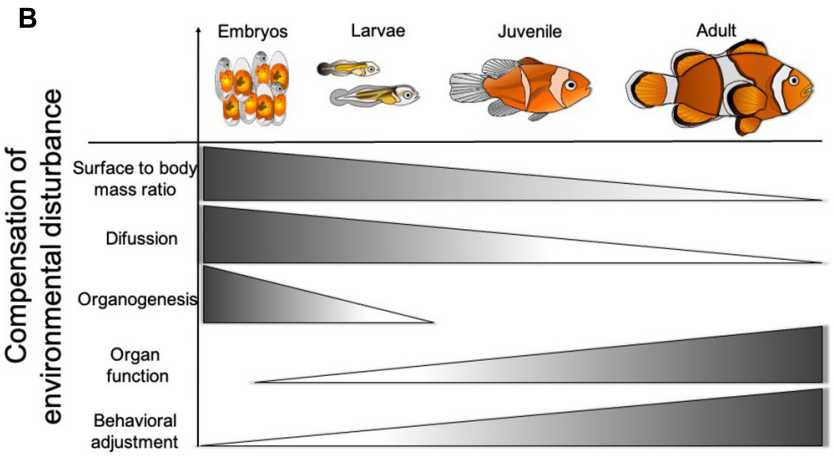

D

\begin{tabular}{|lcc|}
\hline & \multicolumn{3}{c|}{$\begin{array}{c}\text { Mode of inheritance } \\
\text { Genetic }\end{array}$} & Non-genetic \\
\hline Change in DNA sequence & Yes & No \\
Number of affected individuals & Few & Several if not all \\
$\begin{array}{l}\text { Is the change associated with future } \\
\text { biological significance? }\end{array}$ & Yes & Yes \\
$\begin{array}{l}\text { Selective pressure imposed by environmental } \\
\text { disturbance to induce a change }\end{array}$ & High & Low \\
$\begin{array}{l}\text { Fidelity of transmission of effect to } \\
\text { subsequent generations }\end{array}$ & High & Low \\
\hline $\begin{array}{l}\text { Is the change advantageous (A), neutral (N), or disadvantageous (D), under these } \\
\text { scenarios? }\end{array}$ & N & A \\
\hline $\begin{array}{l}\text { Weather } \\
\text { Climate } \\
\text { Climate change }\end{array}$ & N/A & A \\
\hline
\end{tabular}

FIGURE 1 | Factors affecting the variability of plastic and adaptive responses to environmental change. (A) Strength of selection induced by different time-scale events of climate change. The gray line depicts variation in a measured variable (e.g., temperature) in a "real world scenario" highlighting the mismatch with the classic experimental approach of choosing stepwise/discrete mean values (red bars) at different time scales. D, day and N, night; (B) Factors affecting the variability in plastic responses from embryonic to adult developmental stages. Triangles represent the absence (white) and the emergence/presence (dark) of these factors across development; (C) Strength of selection on life-history traits at the species level. Colored lines represent two extremes (slow/small/short = solid lines vs. fast/large/long = dotted lines) for each trait, each line should be interpreted under independent $y$ axis; and (D) Comparison of the influence of the mode of inheritance (genetic vs. non-genetic) for trans-generational effects affecting individual survival and population maintenance under climatic change events.

consideration of multi-stressor interactions will render a better understanding of the effects of climate change.

\section{VARIABILITY IN PLASTIC RESPONSES WITHIN A GENERATION}

\section{Developmental Stage}

Individual plastic responses to weather and climate events are expected to vary across developmental stages. Embryonic and larval stages are considered to be more sensitive to variable environmental conditions in comparison to adult stages, because of reduced plastic capacity (Burggren and Bautista, 2019; Dahlke et al., 2020). Inherent to early development is the progressive maturing of rudimentary morphological structures and physiological functions that allow organisms to regulate homeostatic disturbances (Figure 1B). In fish for example, as development progresses and the surface to body mass ratio decreases, homeostatic regulation by diffusion through skin is gradually replaced by the interrelated functions of the forming organ systems (Rombough, 1998, 2002; Burggren et al., 2017).
During organogenesis, disturbances induced by challenging environmental conditions can compromise the survival of early life stages (Réalis-Doyelle et al., 2016). However, if they survive, the effects can remain present later in life potentially compromising metabolic rates, reproduction, and population replenishment (Jonsson and Jonsson, 2014; Durtsche et al., 2021). In contrast, the experience of environmental challenges early in life can also have positive phenotypic effects. For example, improvement of skeletal development (faster mineralization) was reported in larvae of the seabass exposed to hypercapnic conditions (Crespel et al., 2017). Worth mentioning is the fact that early exposures in life can also lead to positive effects in later developmental stages and not only at the exposed stage (Gobler and Talmage, 2013; Vanderplancke et al., 2015; Spinks et al., 2019). For instance, zebrafish embryos incubated up to hatching in colder or warmer temperatures, exhibited improved swimming performance as adults when exposed to temperatures resembling their temperature of incubation (Scott and Johnston, 2012). However, to date we still have poor understanding of the plastic capacities at the whole organismal level in developing organisms (e.g., thermal limits and tolerance 
ranges), as well as of the actual partitioning of their regulatory mechanisms in organ and systems (e.g., acid-base regulation), and the potential trade-offs with other traits, when facing environmental disturbances (West-Eberhard, 2003; Burggren and Bautista, 2019). This lack of knowledge mainly arises from the intrinsic complexity of studying the effects of climate change in tiny sized organisms, and the inherent technological challenge of developing and implementing reproducible techniques for such specialized measurements.

Although adult life stages exhibit well established physiological acid-base and thermoregulatory capacities, as well as the capacity for adjusting their behavior in response to their surrounding environment, their plasticity and susceptibility to environmental disturbances can vary depending on their reproductive status. Indeed, scenario-based projections of climate change suggest that spawning adults have significantly narrower thermal tolerances (Dahlke et al., 2020). In addition, environmental variation can induce alteration in neuroendocrine pathways, modifying metabolism, disrupting homeostasis and exacerbating production of reactive oxygen species, leading to acceleration of development and aging (Burraco et al., 2020). Therefore, different developmental stages are likely to respond to stressors through distinct mechanisms and with different sensitivity and plasticity. Because populations are composed of individuals of different developmental stages, a particular sensitivity or lack of plasticity in one of the stages may lead to the collapse of the entire population. Therefore, investigating the effects of weather and climate events in all developmental life stages is crucial to provide more reliable information on how populations could be affected by future conditions (Figure 1B).

\section{Life History Traits}

Availability of resources varies with seasonality and across habitats with different environmental conditions. Furthermore, organisms' life history traits represent how variable the environmental changes are in their habitat (Hovel et al., 2017; Chaparro-Pedraza and de Roos, 2019). Consequently, changes in the species geographic distribution and its realized niche induced by climate variability can impact these traits (de Roos and Persson, 2013; Wang et al., 2020; Chaudhary et al., 2021). For example, the reproductive strategies of the majority of species depend on environmental conditions (e.g., temperature, salinity, light:dark cycles, and food availability). Therefore, a delay or acceleration in the timing for reproduction in semelparous species -characterized by death after first reproduction- can lead to a phenological mismatch between larval exogenous feeding and food availability (Durant et al., 2007; Renner and Zohner, 2018), increasing mortality and compromising effective population size (Figure 1C). In comparison, iteroparous species with multiple reproduction events in their lifetime- may be more capable of buffering the effects of climate variability by regulating parental investment across their clutches (Parker, 2002; Cayuela et al., 2014), although long-term and recurrent scenarios may still threaten population recruitment. Therefore, as different species perceive the changes in environmental conditions depending on the granularity of the habitat that they inhabit (Levins, 1968; van Tienderen, 1991, 1997), it becomes necessary to consider the species' dispersal needs and capacities as well as their migration patterns -if present- when interpreting results from experimental studies (Figure 1C).

The effects of climate change can also affect species differentially based on their lifespan and generation time. For example, in comparison to taxa with short-generation times (benthopelagic and reef fishes; up to 5 years), accelerated development and life histories due to global warming can lead to lower mortality and higher fecundity earlier in life in taxa with long-generation times (elasmobranch, bathydemersal, demersal; over 10 years) (Wang et al., 2020). In addition, simulation models suggest that species that possess long lifespans, relative to the change in environmental conditions, may be more plastic in comparison to species with short lifespan (Ratikainien and Kokkoo, 2020). Overall, the differential responses related to lifespan and generational time of a particular species will induce inter- and trans-generational effects that will affect the number of generations experiencing climate variability as well as the species potential for evolutionary adaptation (Figure 1C).

\section{BEYOND A SINGLE GENERATION: TRANS-GENERATIONAL ACCLIMATION AND ADAPTATION}

\section{Evolutionary Adaptation}

Within-generational phenotypic plasticity allows organisms to face the challenges directly imposed by variable environmental conditions. However, to persist in the long-term, populations must cope with the continuous environmental challenges through adaptation across generations. Adaptation occurs through genetic inheritance, i.e., evolution (McGuigan et al., 2021; Figure 1D). For evolution (genetic adaptation) to occur, empirical evidence must demonstrate that the environmental fluctuations due to climate change can lead to modifications in genetic sequences, and that these changes are the result of natural selection (Merilä and Hendry, 2014; Ehrenreich and Pfennig, 2016). The new environmental pressures are likely to induce selection on specific fitness-related traits, resulting in the shift of the allele frequencies of these traits across generations (Bernatchez, 2016; Manhard et al., 2017). Micro evolutionary changes can occur across a small number of generations and at ecological relevant timescales (Hairston et al., 2005; Carroll et al., 2007; Bell and Aguirre, 2013; Hendry et al., 2018; Reznick et al., 2019). However, the species' evolutionary potential may still be low when the rate of change in the environmental conditions outpaces the rate of the species adaptation. For example, a recent study on thermal tolerance in zebrafish artificially selected over six generations to increase or decrease their upper thermal tolerance, reported that these fish exhibited a slow rate of adaptation compared to the rate of global warming, suggesting that such tropical species may meet adaptive constraints when facing global warming (Morgan et al., 2020).

Taken together these studies highlight the need for determining whether adaptation from existing genetic variation 
A
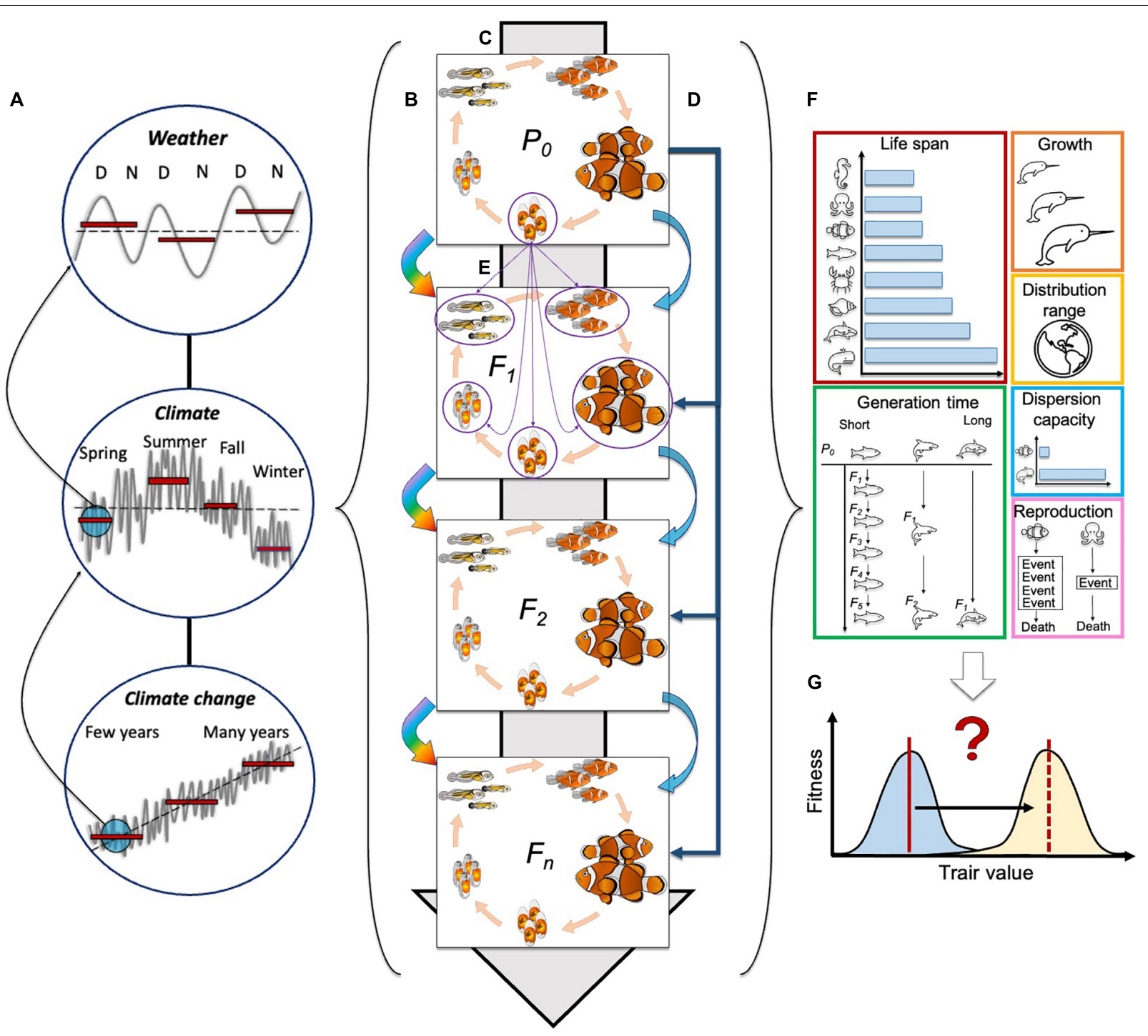

FIGURE 2 | Challenges of within- and trans-generational effects of climatic events on life history traits of species. (A) The different scales in the continuum between weather and climate change impose varied selection pressures (e.g., stochastic, cyclic, and unpredictable) on individuals and populations within- and across generations. D, day and N, night; (B) Climatic events will impose within-generational effects to each generation per se (depicted by surrounding squares for each generation); (C) Trans-generational effects could occur through genetic inheritance (gray background arrow) with transmission of DNA sequences under selection by the environmental conditions across generations; (D) The experience of climatic events on a parental generation alone can also lead to non-genetic

trans-generational effects on its subsequent generations (dark blue arrows). Moreover, the experience of climatic events on the $F_{1}, F_{2}$ and, $F_{n}$, generation per se can also affect their subsequent generation (light blue arrows). (E) A question to be answered yet embraces the trans-generational implications of how the experience of climatic events at specific life stages will affect the different life stages. For example: how experience of climatic events at the egg stage will affect phenotypic traits of eggs, embryos, larvae, juveniles and adults, of the following generation? (purple arrows). (F) The effects of climatic events will vary among species according to their life history traits. Here we illustrate how the variation in life span, generation time, growth, distribution range, dispersion capacity and reproductive events in different species could be differentially affected by changes in environmental conditions. The impact of life history traits across generations is represented with rainbow arrows. (G) Still yet to be answered (?) is if the effects of climatic events (white arrow) will induce a shift (black solid line) of the existing optimum of a trait (blue shaded curve - red solid line) toward a new optimum of the trait (yellow shaded curve - red dotted line) and if this change/adaptation will happen to a rate fast enough to allow species to cope with the effects of climate change.

within populations would be sufficient to cope with the rate of change of climatic variables.

\section{Non-genetic Inheritance}

The adaptability of future generations to fluctuating environments can also be influenced by non-genetic inheritance and can happen from one generation to the next (Ezard et al., 2014; Ryu et al., 2018; Bautista and Burggren, 2019; Cavieres et al., 2020). Although not completely understood, the mechanisms responsible for this type of trans-generational acclimation include, maternal provisioning, microbiome transfer, inheritance of epigenetic markers (e.g., DNA methylation, 
small RNAs, and histone modifications), and behavioral and cultural processes (Bonduriansky et al., 2012; Burggren, 2016, 2018; Bonduriansky and Day, 2018; Ryu et al., 2018; Bautista et al., 2020; Jablonka and Lamb, 2020; Crespel et al., 2021). Although the role of non-genetic inheritance on adaptation and evolution is still under debate (Laland et al., 2014; Charlesworth et al., 2017), trans-generational effects can be stable and can substantially impact organisms' responses to environmental change over several generations (Ryu et al., 2018; Yin et al., 2019; Jablonka and Lamb, 2020). However, their advantages and disadvantages under the different scenarios of climate change are yet to be determined (Munday, 2014; Morgan et al., 2020; Figure 1D). For instance, transgenerational acclimation is particularly advantageous when the change in environmental conditions is slow, and the environmental correlation between parents and offspring is high (Munday, 2014; Uller et al., 2015; Bernal et al., 2018). However, if trans-generational acclimation moves the mean of the phenotype of interest closer to the fitness optima imposed by the environmental change, the strength of selection may be weakened because individuals with different genotypes but with similar phenotypes -induced by non-genetic mechanismsmay exhibit similar fitness (Falconer and Mackay, 1981; Price et al., 2003; Ghalambor et al., 2007; Wild and Traulsen, 2007). Consequently, the rate of genetic adaptation will likely be slowed down (Huey et al., 2009; Donelson et al., 2019), or it can be eliminated in extreme cases (Price et al., 2003). Therefore, more research is still needed to understand this phenomenon and to determine if its buffering capacity would last long enough across generations to lead to genomic fixation (e.g., genetic assimilation). Nonetheless, modeling suggests that when selection acts on genetic and non-genetic mechanisms in the same systems, adaptation takes place at a faster rate than in systems where selection acts just on one mechanism (Klironomos et al., 2013).

\section{FUTURE CHALLENGES AND APPROACHES}

Finally, we propose a list of future challenges that can help to elucidate knowledge gaps and better predict, validate, and inform conservation and management actions to preserve ecosystems and biodiversity. Therefore, with this perspective we advocate for future studies to focus on describing the evolutionary implications of the interaction between within- and trans-generational responses to climatic events. The inherent complexity of understanding the effects of climate change -at any of its scales- also highlights the need for interdisciplinary efforts among the scientific community (see Figure 2).

Challenge 1: To integrate more realistic and naturally relevant variability of environmental conditions in experimental designs (e.g., stochasticity, daily, or seasonal cycles).

- Include more variability, unpredictable frequency, magnitude, and amplitude of fluctuations in environmental conditions.
- Differentiate the specific effects of weather, climate and climate change events on individual fitness-related traits.

- Consider the interaction between multiple stressors in experimental designs at all scales.

Recommendation: By positioning data loggers in the field, researchers can find information about the magnitude and frequency of natural environmental fluctuations. This information may be also found in public data bases. Microcontrollers (e.g., Arduino, see Drake et al., 2017) or timers can be used on temperature or gas control devices to recreate the fluctuations in experiments. Exposing the studied organisms for different length of time to these conditions will then help to distinguish the impacts of the different climatic events. Furthermore, the recreation of environmental conditions reflecting the interactions between at least two relevant environmental stressors for the organisms (for example among temperature, hypercapnia, hypoxia, $\mathrm{pH}$, and salinity) can be used to provide even more accurate predictions.

Challenge 2: To characterize the effects of climatic events on plastic responses from the cellular to the whole individual level at different developmental stages (embryos, larvae, juveniles, adults, and reproductive adults).

- Document the range of plastic response at the different developmental stages within a population.

- Determine what is the actual partitioning of the roles of specific organs and systems for coping with climatic events as the organism develop.

- Determine the consequences of exposure to climatic events during early life stages for overall species fitness.

Recommendation: For experiments on early development, studies must be guided by specific developmental processes and not by "chronological development." Some things to consider are, for example, when organogenesis or metamorphosis occurs. The use of model species to produce specific knock-out organisms would help to determine the role of specific organs and systems. Experiments on adults could compare the plastic response before, during or after the breeding period in iteroparous species, or at least mention the reproductive status of the individuals under study. Although we acknowledge that there might be technological constraints, we advocate for applying the August Krogh's principle for choosing the right species model to answer the question of interest. Furthermore, analyzing the response of juveniles or adults after an early life stage exposure would provide useful information on the carry-over effects of environmental stress on the species fitness.

Challenge 3: To determine the influence of climatic events (weather, climate, and climate change) on both: individual and combined life-history traits to elucidate its consequences for species resilience.

- Implement more studies considering life history traits to improve experimental designs and interpretation of results.

- Determine the effects of climatic events on the phenology of life history traits. 
Recommendation: Studies could include several species representative of different levels across two opposite extremes of any life-history trait of choice in their design or could design and interpret an experiment based on the life history of the species under study. For example, studies will benefit from using more evolutionary approaches for short generation species while focusing on plastic responses for long generations species. In addition, studies could implement re-location of individuals in field studies (under controlled designs) using translocation approaches to see how life-history traits could be modified by the environment. Because of the inherent complexity of integrating a large number of species in these studies, these challenges may be aided by particularly in mathematical modeling.

Challenge 4: To evaluate the limits - if any - of evolutionary adaptation in response to climate change.

- Document if the genetic heterogeneity of populations will be enough to allow for adaptation and relate it with the biology of the species.

- Determine if microevolution can happen in response to climate change and if the rate would be fast enough to overcome its effects.

Recommendation: Studies could determine if future environmental conditions would be able to induce a shift of the optimum values of fitness traits and life-history traits, as well as to determine if species would be able to gradually improve these changes across generations at a rate faster than climate change. Studies could also compare the evolutionary potential of different populations depending on the level of their genetic background or previous experience to new fluctuating environments (e.g., because of geothermal activity). The difference in the genetic basis of the populations either exposed or not could also be evaluated for each generation. This approach will render more precise documentation of the potential and rate of microevolutionary changes. In addition, these experiments would provide even more accurate predictions by including populations composed of individuals at different developmental stages.

Challenge 5: To estimate the limitations and scope (buffering capacities) that trans-generational effects have for species resilience under climatic scenarios.

- Determine the importance of non-genetic inheritance for overcoming environmental challenges, across several generations, by investigating the interaction between within- and trans-generational responses and the specific mechanisms of inheritance.

\section{REFERENCES}

Andrewartha, S. J., and Burggren, W. W. (2012). Transgenerational variation in metabolism and life-history traits induced by maternal hypoxia in Daphnia magna. Physiol. Biochem. Zool. 85, 625-634. doi: 10.1086/666657

Bautista, N. M., and Burggren, W. W. (2019). Parental stressor exposure simultaneously conveys both adaptive and maladaptive larval phenotypes
- Determine how the within generational response of a population can improve or limit the response of future generations.

- Unravel the interplay between genetic and non-genetic molecular basis of physiological, and behavioral responses that help organisms to cope with climatic events, and if these mechanisms can lead to genetic assimilation.

Recommendation: Studies could determine if populations exposed to new environmental challenges are able to adjust their phenotype, transfer it and improve, or limit the response of their offspring over several generations by using common garden experiments. The studies could at the same time document a variety of the different non-genetic mechanisms (for example maternal provisioning, microbiome transfer, or epigenetic markers) to relate to the phenotypic adjustments. Genetic sequencing can also be used in parallel of epigenetic sequencing, to determine if the sequences under epigenetic regulation in one generation match the sequences under genetic evolution in later generations and how those sequences are involved in further non-genetic mechanisms.

\section{DATA AVAILABILITY STATEMENT}

The original contributions presented in the study are included in the article/supplementary material, further inquiries can be directed to the corresponding author/s.

\section{AUTHOR CONTRIBUTIONS}

$\mathrm{NB}$ and $\mathrm{AC}$ contributed for conceptualization, manuscript drafting, figure preparation, editing, and revision. Both authors approved the manuscript for submission.

\section{FUNDING}

This research was supported by a fellowship from the Kone Foundation (201907804) to AC.

\section{ACKNOWLEDGMENTS}

We thank all the many colleagues who through constructive discussions inspired the thoughts covered in this perspective. We also thank the reviewers for their thoughtful comments that helped to improve the manuscript.

through epigenetic inheritance in the zebrafish (Danio rerio). J. Exp. Biol. 222(Pt 17):jeb.208918.

Bautista, N. M., Crespel, A., Crossley, J., Padilla, P., and Burggren, W. (2020). Parental transgenerational epigenetic inheritance related to dietary crude oil exposure in Danio rerio. J. Exp. Biol. 223(Pt 16):jeb.222224.

Bell, M. A., and Aguirre, W. (2013). Contemporary evolution, allelic recycling, and adaptive radiation of the three- spine stickleback. Evol. Ecol. Res. 15, 377-411. 
Bernal, M. A., Donelson, J. M., Veilleux, H. D., Ryu, T., Munday, P. L., and Ravasi, T. (2018). Phenotypic and molecular consequences of stepwise temperature increase across generations in a coral reef fish. Mol. Ecol. 27, 4516-4528. doi: $10.1111 / \mathrm{mec} .14884$

Bernatchez, L. (2016). On the maintenance of genetic variation and adaptation to environmental change: considerations from population genomics in fishes. J. Fish Biol. 89, 2519-2556. doi: 10.1111/jfb.13145

Bonduriansky, R., Crean, A. J., and Day, T. (2012). The implications of nongenetic inheritance for evolution in changing environments. Evol. Appl. 5, 192-201. doi: 10.1111/j.1752-4571.2011.00213.x

Bonduriansky, R., and Day, T. (2018). Extended Heredity: A New Understanding of Inheritance and Evolution, Vol. 281. Princeton, NJ: Princeton University Press.

Bopp, L., Resplandy, L., Orr, J. C., Doney, S. C., Dunne, J. P., Gehlen, M., et al. (2013). Multiple stressors of ocean ecosystems in the 21st century: projections with CMIP5 models. Biogeosciences 10, 6225-6245. doi: 10.5194/bg-10-62252013

Burggren, W. (2016). Epigenetic inheritance and its role in evolutionary biology: re-evaluation and new perspectives. Biology 5, 1-22. doi: 10.1016/b978-0-12800049-6.00050-0

Burggren, W. (2018). Developmental phenotypic plasticity helps bridge stochastic weather events associated with climate change. J. Exp. Biol. 221:jeb161984.

Burggren, W., and Bautista, N. (2019). Invited review: development of acid-base regulation in vertebrates. Comp. Biochem. Physiol. A Mol. Integr. Physiol. 236, 1-14. doi: 10.5005/jp/books/10618_1

Burggren, W. W., Dubansky, B., and Bautista, N. M. (2017). "Cardiovascular development in embryonic and larval fishes," in Fish Physiology, eds A. K. Gamperl, T. E. Gillis, A. P. Farrell, and C. J. Brauner (Cambridge, MA: Academic Press), 107-184. doi: 10.1016/bs.fp.2017.09.002

Burlakova, L. E., Karatayev, A. Y., Pennuto, C., and Mayer, C. (2014). Changes in Lake Erie benthos over the last 50years: historical perspectives, current status, and main drivers. J. Great Lakes Res. 40, 560-573. doi: 10.1016/j.jglr.2014.02. 008

Burraco, P., Orizaola, G., Monaghan, P., and Metcalfe, N. B. (2020). Climate change and ageing in ectotherms. Glob. Change Biol. 26, 5371-5381. doi: 10.1111/gcb. 15305

Burroughs, W. J. (2007). Climate Change: A Multidisciplinary Approach. Cambridge: Cambridge University Press.

Caldeira, K., and Wickett, E. M. (2005). Ocean model predictions of chemistry changes from carbon dioxide emissions to the atmosphere and ocean. J. Geophys. Res. 110, 1-12.

Carroll, S. P., Hendry, A. P., Reznick, D. N., and Fox, C. W. (2007). Evolution on ecological time-scales. Funct. Ecol. 21, 387-393.

Cavieres, G., Rezende, E. L., Clavijo-Baquet, S., Alruiz, J. M., Rivera-Rebella, C., Boher, F., et al. (2020). Rapid within- and transgenerational changes in thermal tolerance and fitness in variable thermal landscapes. Ecol. Evol. 10, 8105-8113. doi: 10.1002 /ece3.6496

Cayuela, H., Besnard, A., Bonnaire, E., Perret, H., Rivoalen, J., Miaud, C., et al. (2014). To breed or not to breed: past reproductive status and environmental cues drive current breeding decisions in a long-lived amphibian. Oecologia 176, 107-116. doi: 10.1007/s00442-014-3003-x

Chaparro-Pedraza, P. C., and de Roos, A. M. (2019). Environmental change effects on life-history traits and population dynamics of anadromous fishes. J. Anim. Ecol. 88, 1178-1190. doi: 10.1111/1365-2656.13010

Charlesworth, D., Barton, N. H., and Charlesworth, B. (2017). The sources of adaptive variation. Proc. R. Soc. B Biol. Sci. 284:20162864.

Chaudhary, C., Richardson, A. J., Schoeman, D. S., and Costello, M. J. (2021). Global warming is causing a more pronounced dip in marine species richness around the equator. Proc. Natl. Acad. Sci. 11:e2015094118. doi: 10.1073/pnas. 2015094118

Crespel, A., Miller, T., Rácz, A., Parsons, K., Lindström, J., and Killen, S. (2021). Density influences the heritability and genetic correlations of fish behaviour under trawling-associated selection. Evol. Appl. 00, 1-14.

Crespel, A., Zambonino-Infante, J.-L., Mazurais, D., Koumoundouros, G., Fragkoulis, S., Quazuguel, P., et al. (2017). The development of contemporary European sea bass larvae (Dicentrarchus labrax) is not affected by projected ocean acidification scenarios. Mar. Biol. 164:155.

Crozier, L. G., and Hutchings, J. A. (2014). Plastic and evolutionary responses to climate change in fish. Evol. Appl. 7, 68-87.
Dahlke, F. T., Wohlrab, S., Butzin, M., and Pörtner, H.-O. (2020). Thermal bottlenecks in the life cycle define climate vulnerability of fish. Science 369, 65-70.

Darling, E. S., and Côté, I. M. (2008). Quantifying the evidence for ecological synergies. Ecol. Lett. 11, 1278-1286.

de Roos, A. M., and Persson, L. (2013). Population and Community Ecology of Ontogenetic Development. Princeton, NJ: Princeton University Press.

Dixson, D. L., Jennings, A. R., Atema, J., and Munday, P. L. (2015). Odor tracking in sharks is reduced under future ocean acidification conditions. Glob. Change Biol. 21, 1454-1462.

Donelson, J. M., Sunday, J. M., Figueira, W. F., Gaitán-Espitia, J. D., Hobday, A. J., Johnson, C. R., et al. (2019). Understanding interactions between plasticity, adaptation and range shifts in response to marine environmental change. Philos. Trans. R. Soc. B Biol. Sci. 374, 1-14.

Drake, M. J., Miller, N. A., and Todgham, A. E. (2017). The role of stochastic thermal environments in modulating the thermal physiology of an intertidal limpet, Lottia digitalis. J. Exp. Biol. 220, 3072-3083.

Durant, J., Hjermann, D., Ottersen, G., and Stenseth, N. (2007). Climate and the match or mismatch between predator requirements and resource availability. Clim. Res. 33, 271-283.

Durtsche, R. D., Jonsson, B., and Greenberg, L. A. (2021). Thermal conditions during embryogenesis influence metabolic rates of juvenile brown trout Salmo trutta. Ecosphere 12, 1-14.

Ehrenreich, I. M., and Pfennig, D. W. (2016). Genetic assimilation: a review of its potential proximate causes and evolutionary consequences. Ann. Bot. 117, 769-779.

Ezard, T. H. G., Prizak, R., and Hoyle, R. B. (2014). The fitness costs of adaptation via phenotypic plasticity and maternal effects. Funct. Ecol. 28, 693-701.

Falconer, D. S., and Mackay, T. F. C. (1981). Introduction to Quantitative Genetics, 2nd Edn. New York, NY: Longman Group.

Faria, A. M., Lopes, A. F., Silva, C. S. E., Novais, S. C., Lemos, M. F. L., and Gonçalves, E. J. (2018). Reproductive trade-offs in a temperate reef fish under high pCO2 levels. Mar. Environ. Res. 137, 8-15.

Ghalambor, C. K., McKay, J. K., Carroll, S. P., and Reznick, D. N. (2007). Adaptive versus non-adaptive phenotypic plasticity and the potential for contemporary adaptation in new environments. Funct. Ecol. 21, 394-407.

Gienapp, P., Teplitsky, C., Alho, J. S., Mills, J. A., and Merilä, J. (2008). Climate change and evolution: disentangling environmental and genetic responses. Mol. Ecol. 17, 167-178.

Gobler, C. J., and Talmage, S. C. (2013). Short- and long-term consequences of larval stage exposure to constantly and ephemerally elevated carbon dioxide for marine bivalve populations. Biogeosciences 10, 2241-2253.

Hairston, N. G., Ellner, S. P., Geber, M. A., Yoshida, T., and Fox, J. A. (2005). Rapid evolution and the convergence of ecological and evolutionary time. Ecol. Lett. 8, 1114-1127. doi: 10.1111/j.1461-0248.2005.00812.x

Hannan, K. D., Munday, P. L., and Rummer, J. L. (2020). The effects of constant and fluctuating elevated pCO2 levels on oxygen uptake rates of coral reef fishes. Sci. Total Environ. 741:140334. doi: 10.1016/j.scitotenv.2020.140334

Hendry, A. P., Schoen, D. J., Wolak, M. E., and Reid, J. M. (2018). The contemporary evolution of fitness. Ann. Rev. Ecol. Evol. Syst. 49, 457-476. doi: 10.1146/annurev-ecolsys-110617-062358

Hoffmann, A. A., and Sgrò, C. M. (2011). Climate change and evolutionary adaptation. Nature 470, 479-485. doi: 10.1038/nature09670

Hovel, R. A., Carlson, S. M., and Quinn, T. P. (2017). Climate change alters the reproductive phenology and investment of a lacustrine fish, the threespine stickleback. Glob. Change Biol. 23, 2308-2320. doi: 10.1111/gcb. 13531

Huey, R. B., Deutsch, C. A., Tewksbury, J. J., Vitt, L. J., Hertz, P. E., Álvarez Pérez, H. J., et al. (2009). Why tropical forest lizards are vulnerable to climate warming. Proc. R. Soc. B: Biol. Sci. 276, 1939-1948. doi: 10.1098/rspb.2008. 1957

IPCC (2014). “Climate change 2014: synthesis report," in Core Writing Team. Contribution of Working Groups I, II and III to the Fifth Assessment Report of the Intergovernmental Panel on Climate Change, eds R. K. Pachauri and L. A. Meyer (Geneva: IPCC), 151.

Jablonka, E., and Lamb, M. J. (2020). Inheritance Systems and the Extended Synthesis. Cambridge: Cambridge University Press. doi: $10.1017 / 9781108685412$ 
Jenny, J.-P., Francus, P., Normandeau, A., Lapointe, F., Perga, M.-E., Ojala, A., et al. (2016). Global spread of hypoxia in freshwater ecosystems during the last three centuries is caused by rising local human pressure. Glob. Change Biol. 22, 1481-1489. doi: $10.1111 / \mathrm{gcb} .13193$

Johansen, J. L., Nadler, L. E., Habary, A., Bowden, A. J., and Rummer, J. (2021). Thermal acclimation of tropical coral reef fishes to global heat waves. Elife 10, 1-30. doi: 10.7554/eLife. 59162

Jonsson, B., and Jonsson, N. (2014). Early environment influences later performance in fishes. J. Fish Biol. 85, 151-188. doi: 10.1111/jfb. 12432

Klironomos, F. D., Berg, J., and Collins, S. (2013). How epigenetic mutations can affect genetic evolution: model and mechanism. Bioessays 35, 571-578. doi: 10.1002/bies.201200169

Laland, K., Uller, T., Feldman, M., Sterelny, K., Müller, G. B., Moczek, A., et al. (2014). Does evolutionary theory need a rethink? Nature 514, 161-164. doi: $10.1038 / 514161 \mathrm{a}$

Landman, M. J., Van Den Heuvel, M. R., and Ling, N. (2005). Relative sensitivities of common freshwater fish and invertebrates to acute hypoxia. N. Z. J. Mar. Freshw. Res. 39, 1061-1067. doi: 10.1080/00288330.2005.9517375

Le Nohaïc, M., Ross, C. L., Cornwall, C. E., Comeau, S., Lowe, R., McCulloch, M. T., et al. (2017). Marine heatwave causes unprecedented regional mass bleaching of thermally resistant corals in northwestern Australia. Sci. Rep. 7, 1-11. doi: 10.1038/s41598-017-14794-y

Lefevre, S. (2016). Are global warming and ocean acidification conspiring against marine ectotherms? A meta-analysis of the respiratory effects of elevated temperature, high $\mathrm{CO} 2$ and their interaction. Conserv. Physiol. 4, 1-31. doi: 10.1093/conphys/cow009

Leo, E., Kunz, K. L., Schmidt, M., Storch, D., Pörtner, H.-O., and Mark, F. C. (2017). Mitochondrial acclimation potential to ocean acidification and warming of Polar cod (Boreogadus saida) and Atlantic cod (Gadus morhua). Front. Zool. 14:21. doi: 10.1186/s12983-017-0205-1

Levins, R. (1968). Evolution in Changing Environments Some Theoretical Explorations. (MPB-2). Princeton, NJ: Princeton University Press. doi: 10.1515/ 9780691209418

Lüthi, D., Le Floch, M., Bereiter, B., Blunier, T., Barnola, J.-M., Siegenthaler, U., et al. (2008). High-resolution carbon dioxide concentration record 650,000800,000 years before present. Nature 453, 379-382. doi: 10.1038/nature 06949

Malhi, Y., Franklin, J., Seddon, N., Solan, M., Turner, M. G., Field, C. B., et al. (2020). Climate change and ecosystems: threats, opportunities and solutions. Philos. Trans. R. Soc. B Biol. Sci. 375, 1-8. doi: 10.1098/rstb.2019.0104

Manhard, C. V., Joyce, J. E., and Gharrett, A. J. (2017). Evolution of phenology in a salmonid population: a potential adaptive response to climate change. Can. J. Fish. Aquat. Sci. 74, 1519-1527. doi: 10.1139/cjfas-2017-0028

McGuigan, K., Hoffmann, A. A., and Sgrò, C. M. (2021). How is epigenetics predicted to contribute to climate change adaptation? What evidence do we need? Philos. Trans. R. Soc. B Biol. Sci. 376, 1-10. doi: 10.1098/rstb.2020.0119

McLeod, I. M., Rummer, J. L., Clark, T. D., Jones, G. P., McCormick, M. I., Wenger, A. S., et al. (2013). Climate change and the performance of larval coral reef fishes: the interaction between temperature and food availability. Conserv. Physiol. 1, 1-12. doi: 10.1093/conphys/cot024

Merilä, J., and Hendry, A. P. (2014). Climate change, adaptation, and phenotypic plasticity: the problem and the evidence. Evol. Appl. 7, 1-14. doi: 10.1111/eva. 12137

Montgomery, D. W., Simpson, S. D., Engelhard, G. H., Birchenough, S. N. R., and Wilson, R. W. (2019). Rising CO2 enhances hypoxia tolerance in a marine fish. Sci. Rep. 9:15152. doi: 10.1038/s41598-019-51572-4

Morgan, R., Finnøen, M. H., Jensen, H., Pélabon, C., and Jutfelt, F. (2020). Low potential for evolutionary rescue from climate change in a tropical fish. Proc. Natl. Acad. Sci. 117, 33365-33372. doi: 10.1073/pnas.201141 9117

Munday, P. L. (2014). Transgenerational acclimation of fishes to climate change and ocean acidification. F1000prime Rep. 6, 1-7. doi: 10.12703/ P6-99

Parker, T. H. (2002). Maternal condition, reproductive investment, and offspring sex ratio in captive red Junglefowl (Gallus gallus). Auk 119, 840-845. doi: 10.1642/0004-8038(2002)119[0840:MCRIAO]2.0.CO;2
Parmesan, C., and Yohe, G. (2003). A globally coherent fingerprint of climate change impacts across natural systems. Nature 421, 37-42. doi: 10.1038/ nature 01286

Pinsky, M. L., Worm, B., Fogarty, M. J., Sarmiento, J. L., and Levin, S. A. (2013). Marine taxa track local climate velocities. Science 341, 1239-1242. doi: 10.1126/ science. 1239352

Pistevos, J. C. A., Nagelkerken, I., Rossi, T., and Connell, S. D. (2016). Antagonistic effects of ocean acidification and warming on hunting sharks. Oikos 126, 1-21. doi: 10.1111/oik.03182

Price, T. D., Qvarnström, A., and Irwin, D. E. (2003). The role of phenotypic plasticity in driving genetic evolution. Proc. R. Soc. Lond. Ser. B Biol. Sci. 270, 1433-1440. doi: 10.1098/rspb.2003.2372

Qui-Minet, Z. N., Coudret, J., Davoult, D., Grall, J., Mendez-Sandin, M., Cariou, T., et al. (2019). Combined effects of global climate change and nutrient enrichment on the physiology of three temperate maerl species. Ecol. Evol. 9, 13787-13807. doi: 10.1002/ece3.5802

Rasconi, S., Gall, A., Winter, K., and Kainz, M. J. (2015). Increasing water temperature triggers dominance of small freshwater plankton. PLoS One 10:e0140449. doi: 10.1371/journal.pone.0140449

Ratikainen, I. I. and Kokko, H. (2019). The coevolution of lifespan and reversible plasticity. Nature Commun. 10, 1-7. doi: 10.1038/s41467-019-08502-9

Réalis-Doyelle, E., Pasquet, A., De Charleroy, D., Fontaine, P., and Teletchea, F. (2016). Strong effects of temperature on the early life stages of a cold stenothermal fish species, Brown Trout (Salmo trutta L.). PLoS One 11:e0155487. doi: 10.1371/journal.pone.0155487

Renner, S. S., and Zohner, C. M. (2018). Climate change and phenological mismatch in trophic interactions among plants, insects, and vertebrates. Ann. Rev. Ecol. Evol. Syst. 49, 165-182. doi: 10.1146/annurev-ecolsys-110617062535

Reznick, D. N., Losos, J., and Travis, J. (2019). From low to high gear: there has been a paradigm shift in our understanding of evolution. Ecol. Lett. 22, 233-244. doi: 10.1111/ele.13189

Rombough, P. (2002). Gills are needed for ionoregulation before they are needed for O2 uptake in developing zebrafish, Danio rerio. J. Exp. Biol. 205, 1787-1794. doi: $10.1242 /$ jeb.205.12.1787

Rombough, P. J. (1998). Partitioning of oxygen uptake between the gills and skin in fish larvae: a novel method for estimating cutaneous oxygen uptake. J. Exp. Biol. 201, 1763-1769. doi: 10.1242/jeb.201.11.1763

Rosa, R., Baptista, M., Lopes, V. M., Pegado, M. R., Ricardo Paula, J., Trübenbach, K., et al. (2014). Early-life exposure to climate change impairs tropical shark survival. Proc. R. Soc. B Biol. Sci. 281:20141738. doi: 10.1098/rspb.2014. 1738

Rummer, J. L., Couturier, C. S., Stecyk, J. A. W., Gardiner, N. M., Kinch, J. P., Nilsson, G. E., et al. (2014). Life on the edge: thermal optima for aerobic scope of equatorial reef fishes are close to current day temperatures. Glob. Change Biol. 20, 1055-1066. doi: 10.1111/gcb.12455

Ryu, T., Veilleux, H. D., Donelson, J. M., Munday, P. L., and Ravasi, T. (2018). The epigenetic landscape of transgenerational acclimation to ocean warming. Nat. Clim. Change 8, 504-509. doi: 10.1038/s41558-018-0159-0

Ryu, T., Veilleux, H. D., Munday, P. L., Jung, I., Donelson, J. M., and Ravasi, T. (2020). An epigenetic signature for within-generational plasticity of a reef fish to ocean warming. Front. Mar. Sci. 7:284. doi: 10.3389/fmars.2020.00284

Scott, G. R., and Johnston, I. A. (2012). Temperature during embryonic development has persistent effects on thermal acclimation capacity in zebrafish. Proc. Natl. Acad. Sci. 109, 14247-14252. doi: 10.1073/pnas.120501 2109

Sheppard-Brennand, H., Soars, N., Dworjanyn, S. A., Davis, A. R., and Byrne, M. (2010). Impact of ocean warming and ocean acidification on larval development and calcification in the sea urchin Tripneustes gratilla. PLoS One 5:e11372. doi: 10.1371/journal.pone.0011372

Spinks, R. K., Munday, P. L., and Donelson, J. M. (2019). Developmental effects of heatwave conditions on the early life stages of a coral reef fish. J. Exp. Biol. 222, 1-16. doi: $10.1242 /$ jeb.202713

Thomas, C. D., Cameron, A., Green, R. E., Bakkenes, M., Beaumont, L. J., Collingham, Y. C., et al. (2004). Extinction risk from climate change. Nature 427, 145-148. doi: 10.1038/nature02121 
Uller, T., English, S., and Pen, I. (2015). When is incomplete epigenetic resetting in germ cells favoured by natural selection? Proc. R. Soc. B Biol. Sci. 282, 1-8. doi: $10.1098 /$ rspb.2015.0682

van Tienderen, P. H. (1991). Evolution of generalists and specialists in spatially heterogeneous environments. Evolution 45, 1317-1331. doi: 10.1111/j.15585646.1991.tb02638.x

van Tienderen, P. H. (1997). Generalists, specialists, and the evolution of phenotypic plasticity in sympatric populations of distinct species. Evolution 51, 1372-1380. doi: 10.1111/j.1558-5646.1997.tb01460.x

Vanderplancke, G., Claireaux, G., Quazuguel, P., Madec, L., Ferraresso, S., Sévère, A., et al. (2015). Hypoxic episode during the larval period has long-term effects on European sea bass juveniles (Dicentrarchus labrax). Mar. Biol. 162, 367-376. doi: 10.1007/s00227-014-2601-9

Wang, H.-Y., Shen, S.-F., Chen, Y.-S., Kiang, Y.-K., and Heino, M. (2020). Life histories determine divergent population trends for fishes under climate warming. Nat. Commun. 11, 1-9. doi: 10.1038/s41467-02017937-4

West-Eberhard, M. J. (2003). Developmental Plasticity and Evolution. New York, NY: Oxford University Press. doi: 10.1093/oso/9780195122343.001. 0001

Wild, G., and Traulsen, A. (2007). The different limits of weak selection and the evolutionary dynamics of finite populations. J. Theor. Biol. 247, 382-390. doi: 10.1016/j.jtbi.2007.03.015

Willis, C. G., Ruhfel, B., Primack, R. B., Miller-Rushing, A. J., and Davis, C. C. (2008). Phylogenetic patterns of species loss in Thoreau's woods are driven by climate change. Proc. Natl. Acad. Sci. 105, 17029-17033. doi: 10.1073/pnas. 0806446105

Yin, J., Zhou, M., Lin, Z., Li, Q. Q., and Zhang, Y. Y. (2019). Transgenerational effects benefit offspring across diverse environments: a meta-analysis in plants and animals. Ecol. Lett. 22, 1976-1986. doi: 10.1111/ele.13373

Zhang, Y., Loreau, M., He, N., Wang, J., Pan, Q., Bai, Y., et al. (2018). Climate variability decreases species richness and community stability in a temperate grassland. Oecologia 188, 183-192. doi: 10.1007/s00442-018-4208-1

Conflict of Interest: The authors declare that the research was conducted in the absence of any commercial or financial relationships that could be construed as a potential conflict of interest.

Publisher's Note: All claims expressed in this article are solely those of the authors and do not necessarily represent those of their affiliated organizations, or those of the publisher, the editors and the reviewers. Any product that may be evaluated in this article, or claim that may be made by its manufacturer, is not guaranteed or endorsed by the publisher.

Copyright (c) 2021 Bautista and Crespel. This is an open-access article distributed under the terms of the Creative Commons Attribution License (CC BY). The use, distribution or reproduction in other forums is permitted, provided the original author(s) and the copyright owner(s) are credited and that the original publication in this journal is cited, in accordance with accepted academic practice. No use, distribution or reproduction is permitted which does not comply with these terms. 